\title{
ARTIGOS
}

\section{TRANSFAKE E A BUSCA PELA VERDADE NA REPRESENTAÇÃO DE TRAVESTIS E PESSOAS TRANS}

\section{Sofia Ricardo Favero ${ }^{1}$ João Gabriel Maracci²}

Resumo: O presente artigo discute o modo que os ativismos trans têm criticado a interpretação de atores e atrizes cis que representam papéis sobre transexualidade em produções cênicas. A essas atuações são dadas o título de transfake, em uma tentativa de reescrever os efeitos do blackface na população trans. Diante disso, buscou-se questionar o modo que a expressão fake estaria, em oposição, mantendo um regime de verdade em relação ao gênero, prática comum na história da nosologia psiquiátrica, mas que pode ser encontrada em determinadas condutas ativistas atuais. Nesse sentido, as disputas pela representação têm aparecido como um meio de impedir a relativização da transexualidade, pois, embora objetivem promover o reconhecimento político das pessoas trans, também presumem determinada correspondência entre aquilo que se é e aquilo se faz. Considera-se, portanto, que existem riscos envolvidos na defesa de uma estabilidade identitária, por meio da censura e técnicas proibitivas, além dos riscos de promover um engessamento das possibilidades de representar a vida.

Palavras-chave: Ativismos trans; Transfake; Representação; Verdade.

\section{Introdução}

Os debates em torno de representação no âmbito cênico têm sido cada vez mais comuns dentro dos ativismos LGBTs, embora não tenham sido sempre tão expressivos.

\footnotetext{
${ }^{1}$ Mestranda pelo Programa de Pós-Graduação em Psicologia Social e Institucional da Universidade Federal do Rio Grande do Sul (UFRGS). Graduada em Psicologia pela Faculdade Pio Décimo.

${ }^{2}$ Mestrando pelo Programa de Pós-Graduação em Psicologia Social e Institucional da UFRGS. Graduado em psicologia pela Pontifícia Universidade Católica do Rio Grande do Sul.
}

Vol. 01, N. 04, Out. - Dez., 2018 - www.revistas.unilab.edu.br/index.php/rebeh 
Filmes como Meninos Não Choram (1999) e Transamérica (2005), que abordam a temática da transexualidade, não provocaram, em suas épocas de lançamento, reações como as que os filmes Clube de Compras Dallas (2013) e Garota Dinamarquesa (2015) suscitaram recentemente. Apesar de serem histórias que compartilham a referência de atores e atrizes cisgêneros ${ }^{3}$ interpretando personagens transgêneros, tais produções não foram interpeladas pelas mesmas críticas - fenômeno que entendemos como fruto de um processo de maior politização das identidades, além de se tratar de uma pauta que, em linhas gerais, reflete expressivamente na mídia.

Pode-se citar a interpretação de Jared Leto, como a transexual Rayon no filme Clube de Compras Dallas (2013), como um eixo central dos apontamentos ativistas sobre os limites e potências da representação. Não que os debates sobre estar representado "identitariamente" tenham se iniciado a partir dessa película, mas definitivamente ganharam mais força após seu lançamento - ou até mesmo na época de sua produção. Representação não se trata, tampouco, de algo surgido no interior dos ativismos LGBTs, mas que podia ser visto anteriormente nos movimentos raciais.

Frente a esse mesmo cenário de críticas, a atriz Scarlett Johansson desistiu recentemente de filmar a película $R u g$ e Tug, do diretor Rupert Sanders, após a repercussão negativa de sua escalação nas redes sociais. Nesse filme, Scarlett interpretaria Dante, um homem trans que viveu na década de 1970. Entretanto, não se tratou da primeira vez que Johansson foi criticada por desempenhar um papel no cinema, pois no filme $O$ Vigilante do Amanhã (2017) também foi apontada negativamente por dar vida a uma personagem asiática.

No contexto de produções brasileiras, destacam-se o filme Elvis \& Madona (2010), a série Tapas e Beijos (2011) e a novela A Força do Querer (2017), que apresentaram o mesmo quadro de pessoas cis interpretando pessoas trans. E, apesar de ser uma prática comum há pelo menos duas décadas na televisão aberta, tendo como grande exemplo a personagem Ramona vivida pela atriz Cláudia Raia na novela As Filhas da Mãe (2001), foi apenas recentemente que esse tipo de contratação passou a ser problematizada, com destaque para a novela A Força do Querer (2017), que despertou

\footnotetext{
${ }^{3}$ De acordo com Jesus (2015), cisgênero é referente às pessoas que se identificam com o gênero que lhes foi designado ao nascer. Sendo assim, tratam-se dos homens e mulheres que, no momento do nascimento, foram caracterizados como do sexo masculino e feminino, respectivamente.
}

Vol. 01, N. 04, Out. - Dez., 2018 - www.revistas.unilab.edu.br/index.php/rebeh 
uma série de desaprovações por parte de alguns setores dos ativismos trans. A autora dessa novela, Glória Perez, foi alvo de diversas críticas devido à sua decisão de contratar a atriz Carol Duarte para interpretar Ivan, um homem transexual. O Movimento Transgente $^{4}$ foi um dos mobilizadores dessas críticas, criando um abaixo-assinado para que homens trans fossem contratados no lugar de Carol Duarte.

É nesse sentido que a ideia da representação aparece no presente trabalho como um conceito fundamental para pensar as implicações nos ativismos LGBTs e feministas, que têm apresentado posturas críticas à atuação de pessoas cis, sejam elas no teatro ou no cinema, quando desempenham personagens trans. Nesses dois campos, as discussões em torno da representação não são novas, mas têm se intensificado ao longo dos últimos anos. De fato, algumas teóricas feministas, como Judith Butler (2015), já pensavam a representação como uma questão complexa e contraproducente para os diferentes feminismos, como é ilustrado no primeiro capítulo do livro Problemas de Gênero. Para a autora, "Talvez, paradoxalmente, a ideia de representação só venha realmente a fazer sentido para o feminismo quando o sujeito mulheres não for presumido em parte alguma" (BUTLER, 2015, p. 25).

Embora se esteja problematizando a categoria "mulher" como um sujeito do feminismo, essa é uma perspectiva que aponta caminhos para compreender como a representação é uma estratégia que surge como inclusiva, em suas mais diversas esferas, mas que também pode promover determinados tipos de exclusão, dado que os domínios da representação também possuem fronteiras (BUTLER, 2015). Sendo assim, alguém sempre fica de fora. Sob tal perspectiva, questiona-se a identidade "mulher" dentro das disputas políticas, se ela seria capaz de articular categorias de união para os sujeitos do feminismo.

Dessa forma, a ideia de representação, aqui, será discutida em relação à mídia, principalmente na interface às demandas de representatividade destinadas pelos ativismos aos meios televisivos, teatrais e cinematográficos, nas quais a questão de pessoas que não possuem determinada identidade de gênero interpretarem personagens das ditas minorias sexuais aparece como polêmica central.

${ }^{4} \mathrm{O}$ abaixo-assinado do Movimento Transgente, junto a uma carta aberta direcionada à novelista Glória Perez, pode ser lido na íntegra em: <http://www.peticaopublica.com.br/pview.aspx?pi=BR92470>. Acesso em: 24 de jul. de 2018.

Vol. 01, N. 04, Out. - Dez., 2018 - www.revistas.unilab.edu.br/index.php/rebeh 


\section{Representação e identidade}

Se as referidas ações apontam para movimentos que visam à restrição de determinados artefatos culturais, culminando eventualmente na sua retirada de circulação, não se pode afirmar que tal contexto se encerra nas demandas e repercussões dos ativismos em nome da identidade e representação. Pelo contrário, práticas restritivas relacionadas à arte - em especial na interface com questões de gênero e sexualidade são temas frequentes de debate no cenário brasileiro contemporâneo, adquirindo centralidade em eventos tais quais os protestos e posterior fechamento da exposição Queermuseu, na cidade de Porto Alegre.

Em similar direção, destacam-se os repetidos cancelamentos institucionais da peça $O$ Evangelho Segundo Jesus, Rainha do Céu, protagonizada por Renata Carvalho, atriz que interpreta Jesus Cristo no espetáculo. A apresentação foi barrada pela Justiça na cidade de Jundiaí, proibida pela prefeitura do Rio de Janeiro e cancelada pelo governo de Pernambuco, onde participaria do Festival de Teatro de Garanhuns - sob a justificativa de evitar controvérsias e eventuais perdas de patrocínio dada a associação entre a figura bíblica e a transgeneridade.

Em termos acadêmicos, a discussão parece ganhar força contemporaneamente a partir dos protestos organizados pelo cancelamento do seminário Os Fins da Democracia, em outubro de 2017, dada a participação e organização da filósofa Judith Butler e sua suposta associação à "ideologia de gênero". O manifesto culminou em ameaças e agressões físicas à mesma e à cientista política Wendy Brown no aeroporto de Guarulhos, após uma mobilização em frente ao evento no dia de sua abertura. Tal acontecimento foi abordado em 8 textos de uma edição temática da revista Cadernos Pagu, publicada em 2018.

Esses exemplos inserem-se em uma rede de acontecimentos socialmente compreendidos - ao menos em um campo de modo geral reconhecido como esquerda sob o viés de "censura", termo usualmente compartilhado com o outro polo do espectro político, à medida que este afirma sofrer, da mesma forma, ações de restrição e proibição a conteúdos que lhe contemplam.

Não buscamos realizar associações lineares entre esses dois campos de práticas e ideias, tampouco afirmar uma estabilidade na dicotomia entre esquerda e direita para a compreensão das disputas atuais no cenário brasileiro. Pelo contrário, a partir da ideia de

Vol. 01, N. 04, Out. - Dez., 2018 - www.revistas.unilab.edu.br/index.php/rebeh 
"censura" e seu singular compartilhamento entre grupos de orientação ideológica oposta, concebemos o termo como um operador conceitual possível para analisar ações e estratégias performadas por agentes relacionados a diferentes espaços deste espectro.

Assim, tomamos a censura não como prática referente a determinado grupo ou vertente política, mas sim enquanto estrutura de ações militantes, transversal ao espectro ideológico no qual se inserem. Desse modo, retomamos as contraposições de Butler (2009) a ações de restrição da linguagem ${ }^{5}$ - como as mobilizações antipornografia - à medida que estas se sustentam em uma contradição performativa. Para proibir uma palavra é necessário dizê-la, e dessa impossibilidade emerge a falha primordial acerca da censura. Como afirma a autora, "a proibição invoca o ato de fala que tenta limitar e fica presa em uma produção circular e imaginária de si mesma” (BUTLER, 2009, p. 217, tradução livre).

Butler (2009), ainda, aponta a concepção de linguagem que opera nas demandas de repressão e embasa investidas de bloqueamento discursivo, centralizada na ideia de que o discurso "age" sobre os sujeitos de forma absoluta. Desse modo, a relação entre representação e ação é tomada enquanto linearidade, culminando em uma estratégia política que não reconhece o sujeito como possível agente frente à linguagem que o totaliza. Dessa forma, restringe-se a representação à medida que esta é compreendida como uma equivalência ou continuidade da prática, evitando-se a primeira como movimento preventivo para a segunda.

No entanto, a teoria da performatividade pode nos auxiliar a uma outra proposta de ação política, não fundamentada pela "certeza" da linguagem, mas sim pelas falhas inerentes à sua constituição. Segundo Butler (2009), é na falha do discurso que emerge a capacidade de agência frente ao mesmo, possibilitando a emergência de um "sujeito" como resposta performativa às interpelações que o inserem na cultura.

Nesse sentido, é a partir da ideia de performatividade, reconhecendo a impossibilidade subjetiva da censura, que buscamos analisar, nas seções abaixo, a emergência de ações contrárias à interpretação de pessoas trans por atores cis no teatro e na televisão. Desse modo, visamos mobilizar a referida discussão acerca da

\footnotetext{
5 Não nos atemos, aqui, à ideia de uma "censura primária", ou seja, aquela que se implica constitutivamente na produção de um sujeito e sua inserção na linguagem, mas sim na compreensão de uma "censura secundária", que diz respeito a uma proibição imposta posteriormente sobre um sujeito (BUTLER, 2009).
}

Vol. 01, N. 04, Out. - Dez., 2018 -www.revistas.unilab.edu.br/index.php/rebeh 
representatividade em interface a um deslocamento no ethos restritivo que comumente embasa a prática ativista. Como aponta Butler (2009, p. 218, tradução livre), "o fracasso da censura na sua tentativa de censurar uma fala em questão tem a ver com: a) a incapacidade de instituir uma subjetivação completa por meios legais e b) a incapacidade para limitar efetivamente o campo social do discurso autorizado”.

\section{Transfake seria o mesmo que blackface?}

Para complexificar a representação, é necessário trazer algumas indagações dos ativismos LGBTs, mais especificamente dos ativismos trans, em relação a essa prática de contratação de atores e atrizes cis para papéis que ilustram vivências trans. De acordo com o Movimento Nacional de Artistas Trans (MONART), em carta aberta ${ }^{6}$ lançada no dia 26 de fevereiro de 2018, a representatividade ${ }^{7}$ é um aspecto fundamental para a garantia de direitos das travestis e pessoas trans. Por esse ângulo, o MONART (2018) inicia sua argumentação fazendo um comparativo entre o que acontece hoje com a população trans e o que ocorreu com a população negra. Além disso, também traz alguns exemplos, como o filme Pantera Negra (2018), para afirmar que seu sucesso deveria impulsionar mais protagonismo de atores e atrizes negras. E, por fim, cita os atores Silvero Pereira e Luis Lobianco como indivíduos cisgêneros que praticam transfake na televisão e no teatro.

Silvero Pereira é conhecido pelo espetáculo teatral BR-Trans, baseado em vivências de pessoas trans, além de ter atuado na novela A Força do Querer (2017) como "Elis", uma travesti motorista. Luis Lobianco, previamente conhecido por trabalhos no canal Porta dos Fundos (Youtube) e no programa Vai Que Cola (GNT), tornou-se alvo de protestos ${ }^{8}$ após a exibição da peça Gisberta, na qual interpretava um monólogo acerca da vida de uma transexual. Ambos os artistas são cisgêneros em papéis sobre transgêneros, e isso fundamentou algumas críticas por parte de determinados ativismos trans, em uma avaliação negativa e parecida com a destinada anteriormente à novela A Força do Querer (2017).

\footnotetext{
${ }^{6}$ Esse documento pode ser acessado em: <https://revistacult.uol.com.br/home/carta-aberta-do-movimentonacional-de-artistas-trans/>. Acesso em: 24 de jul. de 2018.

${ }^{7}$ Representatividade e representação, neste trabalho, são expressões que possuem sentido similar.

8 Para compreender melhor os protestos, uma entrevista com Lobianco pode ser acessada em: $<$ https://extra.globo.com/famosos/ator-sofre-ataques-de-transexuais-durante-peca-chamaram-publico-decriminoso-22528360.html>. Acesso em: 24 de jul. de 2018.
}

Vol. 01, N. 04, Out. - Dez., 2018 - www.revistas.unilab.edu.br/index.php/rebeh 
Uma expressão que ganha força através de sua repetição e destaque, no documento do MONART (2018), é o termo transfake. Em sua carta, transfake aparece diretamente relacionado ao blackface, sendo preciso apresentar o segundo antes de explicar melhor o primeiro. Blackface, nas palavras de Charô Nunes (2013), vai além do ato de vestir-se e pintar-se de negro, sendo também uma prática de disseminação de preconceitos e estereótipos racistas. Nesse sentido, o blackface pode ser caracterizado como algo que perpassa o figurino, mas não só ele, pois precisa estar acompanhado de uma caricatura que busca ridicularizar, diminuir e satirizar a população negra (NUNES, 2013).

Por esse segmento, Djamila Ribeiro (2015) argumenta que o blackface é uma ferramenta de opressão, tendo em vista que se baseia na retratação ultrajante de pessoas negras, por parte de um imaginário racista que exacerba algumas características negroides, como lábios e cabelos, para produzir tal representação grotesca. Pode-se dizer, portanto, que o blackface é definido por seu caráter ofensivo, que expõe homens e mulheres negras de forma pejorativa.

Em contrapartida, o que tem sido visto em certas instâncias dos ativismos trans é um paralelo entre o blackface e o que tem sido chamado de transfake. Trazendo algumas contribuições de Tertuliana Lustosa ${ }^{9}$ (Coletivo Xica Manicongo), durante o seminário "Transfeminismos - Novas perspectivas de Feminismos", a militante afirma que o transfake ocorre quando uma pessoa cis interpreta um personagem trans. Sendo essa, em suas palavras, uma atitude parecida com o blackface. Esse é um ponto de vista que também foi apresentado por meio de outro abaixo-assinado, dessa vez promovido pelo Coletivo T, em abril de 2017, chamado "Representatividade trans já - Diga não ao trans fake" ${ }^{\prime 10}$. Houve, nesse momento, uma aliança entre o Coletivo T e o MONART, contra a exibição da peça Gisberta, nos moldes que estava sendo feita, em Belo Horizonte ${ }^{11}$. Esse é um documento que divulga ter o objetivo de promover a representatividade,

\footnotetext{
${ }^{9}$ Sua entrevista completa pode ser acessada em: <http://comunicacaocolorida.com.br/transartivismorepresentsatividade-visibilidade-transfake-e-luis-lobianco/>. Acesso em: 24 de jul. de 2018.

$10 \mathrm{O}$ abaixo-assinado, que também foi apoiado pelo MONART, pode ser acessado em: <https://www.change.org/p/sated-representatividade-trans-j\%C3\%A1-diga-n\%C3\%A3o-ao-trans-fake>. Acesso em: 24 de jul. de 2018.

${ }^{11}$ Um pouco dessa mobilização pode ser vista em: <https://ponte.org/especial-trans-6/>. Acesso em: 24 de jul. de 2018.
}

Vol. 01, N. 04, Out. - Dez., 2018 -www.revistas.unilab.edu.br/index.php/rebeh 
visibilidade e reconhecimento de pessoas trans nas produções artísticas televisivas, teatrais e cinematográficas.

No manifesto que acompanha esse abaixo-assinado, Renata Carvalho (2018), mencionada atriz que foi alvo de repetidas tentativas de censura, reafirma a conceituação de que o transfake trata-se de um ator cisgênero interpretando um personagem transgênero, além de expor que é devido a isso que surge a ligação com o termo "fake", pois traduz a ideia de falso. Dessa forma, é considerado que o ator cisgênero, ao desempenhar um papel transgênero, estaria produzindo uma representação falsa daquela experiência. Ademais, existe uma semelhança sonora e estética entre as expressões transfake e blackface, fazendo com que o transfake apareça como uma releitura desse fenômeno que historicamente esteve relacionado a pessoas negras.

Essa similaridade dá indícios de que o transfake é um termo que pretende reescrever os efeitos do blackface na população trans. E isso pode ser visto no mesmo manifesto, quando Renata, após citar alguns trabalhos cênicos, sugere que não irá se apegar àqueles que já foram filmados, editados e lançados, “(...) mas usaremos eles como exemplos, torcendo para que um dia isso acabe e que seja tão de mal gosto fazer o Trans Fake, assim como é hoje com o Black Face (quando um ator branco pinta seu rosto de preto)" (CARVALHO, 2018, on-line).

Essa afirmação ilustra como se dão as estratégias de aproximação discursiva entre uma prática e outra, fazendo com que pareçam as mesmas. Todavia, para além dessas correspondências defendidas por alguns ativismos trans, quando afirmam que transfake e blackface são projetos discriminativos análogos, é necessário apresentar também determinados distanciamentos que devem ser levados em consideração.

O blackface, como visto anteriormente a partir de Nunes (2013) e Ribeiro (2015), é uma caricatura que investe em uma ofensa, por meio da utilização de estereótipos raciais, para reforçar um lugar de subalternidade às pessoas negras. Sendo assim, pretende insultar, desfazer e diminuir essa população, tratando-se de um movimento diferente daquele que é percorrido pelo transfake. Se por um lado o blackface tem o objetivo de insultar, aquilo que é chamado de transfake não se baseia necessariamente sob tal premissa. Não é comum encontrar, em grande parte das produções que discutem transexualidade, o objetivo de ofender as pessoas que são trans - isso, evidentemente, 
desconsiderando alguns programas ditos humorísticos, tais como Zorra Total (Rede Globo) e A Praça é Nossa (SBT).

Em filmes como Meninos Não Choram (1999), com o personagem "Brandon" interpretado pela atriz Hilary Swank, ou Transamérica (2005), com a personagem "Bree" interpretada pela atriz Felicity Huffman, assim como em algumas produções televisivas mais recentes, como é o caso da série Transparent (2014), que conta com o ator Jeffrey Tambor no papel de "Maura", não seria prudente afirmar a finalidade de insultar as pessoas trans - embora não seja controlável administrar se os espectadores irão fazer alguma associação com o insulto ou não. O que há, em parte expressiva dessas produções, é a reprodução de uma narrativa psicopatológica, na qual travestis, transexuais e transgêneros aparecem como sujeitos que sofrem.

Enquanto o blackface promove uma caricatura que procura despertar a risada e a chacota, o chamado de transfake pretende sensibilizar, recorrendo a uma ideia de que pessoas trans têm vidas marcadas por uma intensa infelicidade, herdada da tradição médica. Os grandes manuais de saúde, com destaque para a Classificação Internacional de Doenças (CID - 10) e o Manual Diagnóstico e Estatístico de Transtornos Mentais (DSM - 5), estabelecem que as experiências trans são enfermidades, nas quais o sujeito precisa apresentar um quadro diagnóstico de aversão a si mesmo. E essa noção de repugnância ao próprio corpo e insatisfação subjetiva não se instala somente na área da Saúde, mas vai influenciar também as Artes Cênicas. Então, nesse sentido, será visto que os personagens transgêneros em algumas produções televisivas, teatrais ou cinematográficas, estão geralmente submetidos a uma relação conflituosa com quem são. Relação de dor, aflição e angústia.

Sendo assim, é possível assumir que o transfake e o blackface partem de lugares diferentes, pois possuem intenções distintas, não sendo prudente classificar a atuação de atores/as cis como intrinsecamente ofensivas, pois estas não costumam se dar sob um terreno de desrespeito. Entretanto, essa não é uma discussão esgotada, pois o termo transfake ainda aponta reflexões pelo encontro do prefixo "trans" com o adjetivo fake. Embora pareça atual, a relação entre o falso e a transexualidade não é exatamente nova, pelo contrário, trata-se de uma perspectiva que compartilha de propostas advindas da nosologia psiquiátrica.

\section{O "verdadeiro ou falso" do gênero}

Vol. 01, N. 04, Out. - Dez., 2018 - www.revistas.unilab.edu.br/index.php/rebeh 
Na década de 1960, o endocrinologista Harry Benjamin começou a desenvolver o que chamou de "Etiologia do Transexualismo", em sua obra O Fenômeno Transexual (1966). Nesse livro, que obteve destaque na área dos estudos de gênero, principalmente a respeito das identidades transexuais, Benjamin (1966) estabeleceu algumas características diagnósticas para identificar os pacientes que apresentassem um quadro de transexualidade. Baseado nesses critérios, os pacientes seriam diagnosticados enquanto transexuais, fazendo com que recebessem o rótulo de transexuais verdadeiros, caso apresentassem clinicamente o desejo de remover os genitais e combater as características primárias e secundárias do próprio sexo.

Dizemos “identificar" devido a seus esforços terem sido voltados primordialmente à produção de uma explicação acerca das origens do "transexualismo" como era chamada a transexualidade. Para o autor, não poderia haver tratamento voltado a essa questão que não fosse perpassado por um procedimento cirúrgico. Então, naquele momento, existia um foco em elaborar uma justificativa acerca das causas da transexualidade, mas não um tratamento, alegando que não era possível, no caso de um paciente transexual, ajustar o corpo à mente ou a mente ao corpo sem o auxílio de uma cirurgia de redesignação sexual (BENJAMIN, 1966). Essas cirurgias seriam autorizadas após um processo de avaliação clínica, que serviria para reconhecer os transexuais verdadeiros e, assim, operá-los. Todavia, se assumimos que para a literatura médica existia a transexualidade de verdade, é preciso considerar que para esse campo também existia uma transexualidade que era considerada mentira. Como aponta Leite Jr (2011): “o conceito de pessoas 'verdadeiras' só faz sentido e pode se sustentar em oposição às pessoas "falsas"” (p. 174).

Ademais, esse não foi o único trabalho que discutiu gênero e influenciou estudos na área; outros autores também tiveram destaque, como John Money e Patricia Tucker (1981), Robert Stoller (1982) e Gayle Rubin (1993). Mas, expressivamente, as propostas iniciadas em O Fenômeno Transexual se assemelham ao que pouco tempo depois foi apresentado nas edições dos guias CID-09 (1975) e DSM-III (1980). Tais manuais passaram a estabelecer condições para identificação sintomatológica da transexualidade, nessas e em edições posteriores, que definiam ser necessário apresentar, por período mínimo de tempo, uma intensa vontade de pertencer ao sexo oposto, realizar a transgenitalização e minimizar as características primárias e secundárias do próprio

Vol. 01, N. 04, Out. - Dez., 2018 - www.revistas.unilab.edu.br/index.php/rebeh 
sexo. Os pacientes que não apresentassem esses sintomas seriam considerados inaptos a determinados procedimentos cirúrgicos.

No Brasil, pessoas trans que não correspondiam aos critérios diagnósticos da transexualidade, baseados em percepções binárias, passaram a ser classificadas como travestis. Essa é uma questão abordada por Lionço (2009), ao analisar a formulação do Processo Transexualizador (Portaria $n^{\circ}$ 1.707) pelo Sistema Único de Saúde (SUS), uma importante política voltada à população trans, quando a autora discute que a travestilidade incorpora uma androginia que não é permitida à transexualidade, ao menos não pela narrativa psicopatológica. E essa fluidez fez com que as travestis fossem excluídas da concepção inicial dessa política de saúde, pois, segundo os guias de desordem mental, para ser transexual é preciso seguir o roteiro da nosologia psiquiátrica fundamentado na ojeriza a si mesmo. Caso contrário, tratar-se-ia da ocorrência de uma transexualidade artificial - fake.

Neste sentido, a adoção de um critério de veracidade para a experiência do gênero - diferenciando em termos nosográficos o verdadeiro do falso transexual remete-nos às formulações de Butler (2015) acerca da performatividade, que, embora sem abordar especificamente as vivências trans, fornece reflexões acerca dos ideais de autenticidade e linearidade que operam sobre o gênero e a sexualidade na cultura. Para a autora, a performatividade de gênero compreende os mecanismos pelos quais o poder age sobre os corpos a partir de atos de fala ilocucionários - que dão existência àquilo que nomeiam - e perlocucionários - fazendo com que uma série de eventos aconteçam em decorrência do enunciado. A narrativa de descrição e produção do sexo na cena de um nascimento performada no texto "É um menino!" ou "É uma menina!" pode ser relacionada, assim, aos critérios diagnósticos que performam, também no contexto médico, as condições de veridição para uma pessoa ser "de fato" transexual, ou não o suficiente.

No entanto, como visto, as formulações da autora não pressupõem uma ação diretiva ou totalizante do discurso sobre o sujeito. Pelo contrário, a própria experiência humana aponta para os limites e falhas da interpelação na decorrência de uma vida, à medida que enunciados como "É um menino!", por exemplo, comumente se contraponham às formas com que cada sujeito se experimenta e produz a si mesmo em relação à norma na qual se insere. Qual seria, então, a verdade sobre o gênero? Para

Vol. 01, N. 04, Out. - Dez., 2018 - www.revistas.unilab.edu.br/index.php/rebeh 
Butler (2015), não há uma realidade generificada anterior à ação no mundo: é a prática e sua constante repetição de um anterior inalcançável - que afirma a existência de um gênero, de modo que esta mesma citacionalidade promova também a sua subversão, à medida que a repetição sempre está sujeita a falhas e limites.

Assim, a prática repetitiva do gênero não se dá em relação à uma verdade no passado, mas sim a um ideal, constantemente perseguido em práticas que, ao mesmo tempo, apontam para a sua impossibilidade constitutiva. Neste sentido, a impositiva linearidade entre sexo, gênero e desejo, que estabelecem a cis/heterossexualidade compulsória, opera também em um enquadre de reconhecimento possível (às vezes a duras penas) para pessoas trans contempladas pelos critérios diagnósticos de veridição para a sua experiência. Este enquadramento exige, além disso, uma delimitação precisa de suas fronteiras, de modo que a dinâmica do reconhecimento se situe a partir da negação de um outro não reconhecível ou de reconhecimento incerto - movimento que a autora nomeia como abjeção (BUTLER, 2000), ou, mais recentemente, distribuição desigual da precariedade (BUTLER, 2018), conceitos que mantêm em comum as referências à exclusão e violência para aquelas vidas situadas no limite do inteligível.

É por esse ângulo que consideramos arriscada a importação de uma gramática derivada da medicina, tendo em mente que tentativas anteriores de controle da transexualidade, separando-a entre legítima ou fictícia, originaram movimentos de precarização para determinados sujeitos que - por mais que não se identificassem propriamente como transexuais - vivenciavam o gênero para além das expectativas da cis/heterossexualidade compulsória. Nesse ponto, o uso do termo "transfake" pode reafirmar um tipo de prática que justificou décadas de patologização, tendo em vista que as estratégias para diferenciar transexuais entre experiências verdadeiras ou falsas fez com que esses sujeitos se encontrassem, muitas vezes, em relações de poder e tutela na clínica.

É notório que nem todas as problemáticas que aparentemente cabem aos consultórios podem ser vistas socialmente, mas é possível notar pontos de encontro entre a perícia que costuma ser realizada por profissionais de saúde, quando querem avaliar se uma experiência trans é inteligível, e determinadas condutas ativistas, a partir do momento que se colocam na posição de regular quem pode ser trans - ainda que por meio de uma interpretação artística. Essa não se trata de uma associação retilínea, no

Vol. 01, N. 04, Out. - Dez., 2018 - www.revistas.unilab.edu.br/index.php/rebeh 
sentido de buscar características parecidas por parte de dois fenômenos com contextos diferenciados, mas uma reflexão que propõe uma ideia de continuidade entre certas práticas médicas e condutas ativistas.

Entretanto, para evitar isso, não caberia corroborar ainda mais com as fronteiras da transexualidade, mas de bagunçá-las até que o transfake, transfalse ou até mesmo transfantasy fossem possíveis de existir, desestabilizando as estruturas do discurso psicopatológico. De outro modo, não apenas pessoas cis seriam colocadas dentro dessas classificações de falsidade, mas também pessoas trans, como foi a situação das travestis no Brasil (LIONÇO, 2009; LEITE JR, 2011). Cenário que se estendeu até que o Processo Transexualizador fosse redefinido em 2013, incluindo uma linha de cuidado às travestis e acompanhando também a inserção dos homens trans na mesma política.

\section{"Certas ordens de verdade"}

Se, quando pessoas cis interpretam papéis trans, despertam uma repercussão negativa, por parte dos movimentos sociais, no momento que pessoas trans se encarregam dessa tarefa a repercussão se dá de outra forma. E uma situação que ilustra esse ponto é a participação da atriz Laverne Cox na série Orange Is The New Black (2013). A decisão da Netflix, empresa responsável pela série, de contratar uma mulher trans para o papel de uma presidiária transexual reverberou positivamente na mídia e em redes sociais. Por interpretar "Sophia", Laverne chegou a ser indicada ao Emmy (2014), na categoria de Melhor Atriz Convidada Numa Série de Comédia, sendo a primeira mulher trans a obter esse destaque na história da premiação.

Pouco tempo depois, essas contratações passaram a ser cada vez mais comuns. Foi o caso da atriz Jamie Clayton, responsável pelo papel de "Nomi" na série Sense8 (2015), também do serviço de streaming Netflix. Perto desse lançamento, outra produção estrelada por atrizes transexuais foi bastante aclamada, tratou-se do filme Tangerine (2015), uma película interpretada por Kitana Kiki e Mya Taylor, nos papéis de "Sin-Dee Rella" e "Alexandra". Em seguida, a película Una Mujer Fantástica (2017) ganhou a estatueta de Melhor Filme Estrangeiro no Oscar (2018), com a atuação da transexual Daniela Vega no repercutido papel de "Mariana Vidal".

Vol. 01, N. 04, Out. - Dez., 2018 -www.revistas.unilab.edu.br/index.php/rebeh 
Em 2018, a série recém-lançada Pose foi além. O diretor Ryan Murphy decidiu retratar o cenário LGBT de uma Nova York ambientada na década de 1980, e para tanto contratou o maior elenco trans da história da televisão norte-americana. Pose (2018) tem um total de cinco mulheres transexuais em seu quadro de atrizes, entre elas se encontram Angelica Ross, Dominique Jackson, Hailie Sahar, Indya Moore e Mj Rodriguez. Devido a esse fator, a série repercutiu na imprensa estadunidense de maneira otimista, como foi o caso das reviews de alguns veículos de comunicação.

A revista Vanity Fair ${ }^{12}$ classificou a série como ousada e necessária, além de chamar os envolvidos na produção de "cuidadosos" por terem decidido contratar atrizes trans, tanto na parte da atuação quanto na produção, algo que definiram como uma atitude responsável. Nesse mesmo segmento, o jornal The New York Times ${ }^{13}$ considerou a atitude de Ryan Murphy, de contratar atrizes trans, como assídua, no sentido de ter sido pontual às atuais discussões. Por fim, o canal $\mathrm{CNN}^{14}$ fez um comparativo entre Pose (2018) e a série Transparent (2014), afirmando que, diferente da segunda, a série de Murphy deu visibilidade a artistas LGBTs que costumam ser relegados à falta de oportunidades e papéis menores.

Após esse breve panorama, não seria arriscado entender que as atuações de pessoas trans em papéis que condizem com o que elas são, em suas vidas pessoais, é algo que tem sido celebrado pela mídia. E que as pessoas trans que são artistas, de certa forma, têm chamado uma atenção que não compete somente ao tema das produções que são convocadas a participar, mas também devido a uma implicação subjetiva. Não são apenas funcionárias, elas são aquilo que representam. Nesse sentido, levantamos a hipótese de que os personagens trans que são interpretados por pessoas trans conseguem produzir uma veridicção (FOUCAULT, 1999).

Dizemos isso pensando que as atuações de Laverne, Jamie, Mya e tantas outras não têm repercutido somente pelo impacto artístico, mas também pela capacidade de transmitir à audiência um certo tipo de verdade. Tal verdade, no entanto, se dá em razão

\footnotetext{
${ }^{12}$ Para ler a resenha completa da revista, acessar: <https://www.vanityfair.com/hollywood/2018/05/posefx-ryan-murphy-review>. Acesso em: 30 de jul. de 2018.

13 A resenha do jornal pode ser lida na integra em: <https://www.nytimes.com/2018/06/01/arts/television/pose-review-fx-ryan-murphy.html>. Acesso em: 30 de jul. de 2018.

14 Colocando as atrizes trans como centrais no debate, o canal tece alguns comentários em: <https://edition.cnn.com/2018/06/01/entertainment/pose-review/index.html>. Acesso em: 30 de jul. de 2018.
}

Vol. 01, N. 04, Out. - Dez., 2018 - www.revistas.unilab.edu.br/index.php/rebeh 
do contexto que as pessoas trans estão inseridas, isso é, um cenário de violência, falta de empregabilidade, abandono familiar, evasão escolar e outras adversidades. Compreender isso é importante pois, de acordo com Foucault, "a própria verdade tem uma história". (1999, p. 8). E dentro desse processo as pessoas trans surgem como um sujeito que é capaz de produzi-la, considerando que ocupam um lugar central na disputa pela inteligibilidade de gênero.

Nessa perspectiva, Foucault propõe: "atemo-nos a esse sujeito do conhecimento, a este sujeito da representação, como ponto de origem a partir do qual o conhecimento é possível e a verdade aparece.” (1999, p. 10). E sugere que devemos, em contrapartida, entender como ocorre a constituição desse sujeito que não deve ser vista como esgotada, posto que ele é histórico. Assim sendo, compreendemos que as pessoas trans, em grande parte por estarem sujeitas a protocolos que questionam seus gêneros há pelo menos quatro décadas, como foi ilustrado pelos guias de desordens mentais, acabam sofrendo um processo de descredibilização. São vistas como menos mulheres ou menos homens, menos reais ou menos autênticas, podendo ocasionar essa busca por uma representação fiel a quem são.

A partir disso não surpreende ver que Jennifer Boylan, consultora trans da série Transparent (2014), teve de enfrentar duras críticas ${ }^{15}$ em respeito a escalação de um homem cis, o ator Jeffrey Tambor, para interpretar uma mulher trans, respondendo que não pretendia reafirmar o estereótipo de "homem vestido de mulher" que é dado às transexuais por causa do casting. Por esse ângulo, um modo de evitar que o estereótipo seja propagado parece ser a partir da contratação de pessoas que são aquilo que os personagens também são. Em outras palavras, um regime de veridicção, que ocorre pois:

Só pode haver certos tipos de sujeito de conhecimento, certas ordens de verdade, certos domínios de saber a partir de condições políticas que são o solo em que se formam o sujeito, os domínios de saber e as relações com a verdade. (FOUCAULT, 1999, p. 27).

Pessoas trans, dentro dessa disputa, seriam os sujeitos capazes de produzir uma forma de verdade, uma que não depende da qualidade da atuação, mas que aparenta proceder dessa característica "intrínseca” que é o gênero.

Neste sentido, o regime de verdade atua como um campo de possibilidades para o exercício de um sujeito, operando na lógica de reconhecimento para formas que são ou

${ }^{15}$ Essa entrevista está disponível em: <http://qga.com.br/arte-cultura/cinema/2015/09/como-transexuaissao-retratados-na-televisao-e-cinema>. Acesso em: 30 de jul. de 2018.

Vol. 01, N. 04, Out. - Dez., 2018 - www.revistas.unilab.edu.br/index.php/rebeh 
não vivíveis. Constitui-se como um “ponto de referência” para que o sujeito diga quem é e se produza performativamente. $\mathrm{O}$ reconhecimento não fornece uma pré-determinação da vida possível, que atuaria sobre ela de modo diretivo, mas é sim a partir dele que a norma pode ser exercida e também subvertida.

Butler (2015), em diálogo com a obra foucaultiana, aponta que a desestabilização de um regime de verdade desloca também os mecanismos de reconhecimento que fornecem a própria condição ontológica do sujeito. Questionar a si mesmo - ou seja, questionar o enquadre de reconhecimento que opera sobre uma condição de "si" - envolve um risco, à medida que situar-se no limite do reconhecível pode promover, também, uma perda da condição de sujeito, ou até mesmo da condição de "humano" (BUTLER, 2015; FOUCAULT, 2000).

A partir dessa compreensão, entendemos que a demanda acionada por movimentos sociais de que personagens trans sejam interpretados somente por atores que compartilhem deste marcador social opera na produção de um regime de verdade, que fornece um reconhecimento para a transgeneridade na cultura. No entanto, como visto, este reconhecimento se embasa em um ideal de verdade para a transexualidade, relacionado principalmente a uma vivência cotidiana e, por vezes, em diálogo com elementos psicopatológicos.

Poderíamos pensar, nesta direção, que uma representação midiática que não visa a correspondência identitária entre atores e personagens atua na desestabilização do regime de verdade que reitera os mecanismos de reconhecimento das pessoas trans no plano da abjeção? A partir de tal provocação, questionamos quais desafios se impõem à efetivação deste cenário no campo da mídia, e sob que riscos.

\section{Entre ator e personagem}

Por trás do debate sobre representação e reconhecimento, a mídia aparece como um plano de fundo que atravessa a discussão. Se, por um lado, pode ser considerada uma agente na manutenção de estereótipos, por outro tenta ser usada para romper os mesmos estereótipos. Um caso que ilustra essa questão foi o filme brasileiro A Glória e a Graça (2017), com a atriz Carolina Ferraz interpretando uma transexual chamada "Glória".

Vol. 01, N. 04, Out. - Dez., 2018 - www.revistas.unilab.edu.br/index.php/rebeh 
$\mathrm{Na}$ película, Carolina contracenou com a atriz Carol Marra, mulher trans contratada para interpretar "Fedra", uma personagem que também é trans. Quando questionada sobre a escolha de Carolina Ferraz para o papel de uma transexual, Carol respondeu à revista Glamour ${ }^{16}$ que "ela foi uma grande parceira e, pela primeira vez, vamos ver um papel de uma trans real, com vida e sentimentos, e não uma caricatura, como costuma ser apresentada na mídia”. Tal afirmação percorre um caminho interessante, pois, ao passo que aponta uma produção desligada da ideia de caricatura que sustenta as acusações de transfake, também viabiliza condições de representação "humanizadas" que extrapolam a correspondência entre ator e personagem.

Aqui, cabe destacar o modo que a mídia tem sido vista como um espaço de conscientização, principalmente no que se relaciona com as questões de gênero, pois, de acordo com Miskolci e Pelúcio, “a problemática trans atual reatualiza tensões históricas em um momento marcado por novas tecnologias corporais e a disputa por seu acesso com os detentores da expertise médica.” (2017, p. 267). Ademais, o risco que se corre quando é defendido que pessoas trans devem interpretar personagens trans é que, não raramente, esses sujeitos passem a ser contratados apenas para fazer isso. Esse obstáculo foi apontado por Carol Marra durante o período de divulgação do filme A Glória e a Graça (2017), e somente após ter dado vida a diversas transexuais, desde séries como Psi (2014) e Segredos Médicos (2014), é que foi chamada para interpretar uma mulher cis gestante na peça Bruta Flor (2018).

A partir deste rumo surgem duas promessas. Uma de repercussão otimista acerca da interpretação de artistas trans como um instrumento de conscientização, que pode ser vista em declarações supracitadas do MONART (2018) - afirma-se que atores e atrizes trans ajudariam a educar a população sobre gênero, o que, por mais bem intencionado, dificulta a compreensão de que aquilo que fazem trata-se de um trabalho, e não necessariamente uma militância. A segunda seria a promessa de repercussão pessimista a respeito da interpretação de atores cis, pois "homens vestidos de mulher" estariam exibindo uma mentira em suas atuações de personagens trans.

Para combater isso, pode-se criticar, censurar ou até proibir. E aqui o transfake se revela como uma técnica também proibitiva. Evidentemente que poderia ser dito que

16 Para ler o resto da entrevista, acessar o portal virtual da revista em: $<$ https://revistaglamour.globo.com/Celebridades/noticia/2017/03/carol-marra-sobre-ser-trans-nao-e-maisimportante-que-meu-talento.html>. Acesso em: 02 de ago. de 2018.

Vol. 01, N. 04, Out. - Dez., 2018 - www.revistas.unilab.edu.br/index.php/rebeh 
pessoas trans não têm expressão política para proibir pessoas cis de atuar, mas não é dessa forma que interpretamos a problemática atual. Como sustenta Foucault (1994), compreendemos que "existe uma sensível diferença entre as proibições concernentes à sexualidade e as outras formas de proibição. Ao contrário das outras proibições, as sexuais estão sempre ligadas à obrigação de dizer a verdade sobre o si.” (p. 783).

Se reconhecemos que a única verdade a ser considerada em relação a produções cênicas sobre transexualidade é saber quem são os sujeitos por trás dos personagens, os atores cis serão considerados dissimulados - e estaríamos assumindo que conscientizar não é, de fato, a proposta central. Todavia, ao mesmo tempo, caso o gênero fosse a única verdade presumida, culminaria na armadilha de renaturalização das pessoas trans, como apontado por Preciado (2014) ao discutir algumas críticas feministas que colocavam o homem como natural e a mulher como construída socialmente. Dizemos armadilha pois, de forma contraditória, esses processos de regulação identitária entre atores e personagens dão indícios de que pretendem manter a transexualidade protegida de modificações.

Em outras palavras, o anseio pelo fim do transfake, em termos midiáticos, aparenta não estar vinculado somente a uma discussão sobre oportunidades de trabalho, mas a uma busca por inteligibilidade dentro das expressões "homem" e "mulher" que já estão dadas. Em movimento oposto, ainda com Preciado (2014), frente aos escritos de Judith Halberstam, é dito que "drag kings não exibem uma falsa imitação da masculinidade. Pelo contrário, deixam entrever como se constrói a masculinidade autenticamente" (p. 79). Sob esse esforço para anunciar a artificialidade do gênero, a relativização da transexualidade por meio do transfake não seria uma via capaz de perturbar alguns fundamentos essencializantes que afetam pessoas trans?

Nesse sentido, consideramos que a aposta em representatividade acionada pelos ativismos visa a contemplar as trangeneridades em um plano de reconhecimento público e político, fundamental para a luta contra as condições de exclusão e violência que usualmente se relacionam a esta população. No entanto, se tal estratégia reitera uma verdade sobre o gênero - responsabilidade que costumava ser delegada a manuais psiquiátricos -, o reconhecimento acionado afirma a necessidade de critérios de veridicção para a experiência trans, refletindo uma esperada continuidade entre sexo, gênero e desejo.

Vol. 01, N. 04, Out. - Dez., 2018 -www.revistas.unilab.edu.br/index.php/rebeh 


\section{Considerações Finais}

Ao apontar que personagens trans não devem ser interpretados por pessoas cis, sob risco de críticas e problematizações, os movimentos sociais podem acabar (re)essencializando a transexualidade. De fato, pensamos que o uso do termo transfake para mobilizar essa discussão pode ser contraproducente, pois opera dentro de uma lógica de "troca de lugares". Se antes a transexualidade era vista como uma cópia da cisgeneridade, que se mantinha como a "origem" do gênero, nesse embate a transexualidade tem se imposto como verdadeira, colocando a cisgeneridade como fake. Sendo assim, não há uma ruptura com as práticas psicopatológicas de legitimação do gênero, por parte dessas críticas, mas uma continuidade.

Levamos em consideração, ainda, que são esporádicos os filmes, telenovelas ou peças teatrais que retratam um personagem transexual. Sendo assim, a estratégia por ocupar papéis trans em produções cênicas pode, contraditoriamente, situar os próprios artistas trans diante de limitadas alternativas de trabalho. Dito de um modo simples, por que trans tem de interpretar personagem trans?

Sob a concepção de performatividade, entendemos a não existência de um lugar anterior e verdadeiro para o gênero, que se produz, no presente, a partir de práticas interiores a uma norma. Neste sentido, a categoria acionada para o reconhecimento de um sujeito não carrega uma verdade autoevidente - pelo contrário, é na exposição da artificialidade desses critérios que se pode desestabilizar noções arraigadas e mesmo violentas para a produção de um gênero. Por tal perspectiva, se a norma cisgênera opera nas condições de reconhecimento para um sujeito possível, a transgeneridade marca justamente o seu limite, relegada por isso a uma posição de abjeção. Como aponta Butler (2000), a abjeção é constitutiva da norma, posto que expõe a sua fronteira, servindo como espaço necessário para que o domínio do sujeito seja circunscrito. O sujeito, desse modo, constitui-se na força contrária a essa abjeção, situando-a em um exterior a si mesmo, que "está, afinal, 'dentro' do sujeito, como seu próprio e fundante repúdio" (BUTLER, 2017, p. 112).

Os movimentos de restrição e o ethos de censura que opera em protestos contrários aos artefatos midiáticos que contam com a participação de atores cis interpretando pessoas trans inviabiliza, deste modo, desestabilizações possíveis sobre a

Vol. 01, N. 04, Out. - Dez., 2018 - www.revistas.unilab.edu.br/index.php/rebeh 
suposta verdade do gênero e o lugar de abjeção que funda o seu limite a partir de representações diversas. Além disso, como visto, o mecanismo psíquico da censura opera na sua contestação, dado que, como aponta Butler, "a proibição é produtiva" (2017, p. 68). Não por acaso, é justamente o termo censura que conecta as ações restritivas entre grupos de direita e esquerda, que, paradoxalmente, se valem deste mecanismo para coibir as restrições contra as quais afirmam se opor.

Por essa razão, acreditamos que uma flexibilidade nos mecanismos de reconhecimento em termos midiáticos pode ser efetivada não pela associação entre

identidade e representação, mas sim na proliferação de paródias para o gênero, que apostem na exposição de sua artificialidade e contingência. Isso envolve uma participação ativa dos meios midiáticos na contratação de pessoas trans - sem visar a uma congruência entre sua identidade e seu trabalho, mas sim a uma dinamização das possibilidades de representar a vida em termos múltiplos.

\section{Referências}

AMERICAN PSYCHIATRIC ASSOCIATION. Diagnostic and Statistical Manual of Mental Disorders - DSM-III. 3th.ed. Arlington: APA, 1980.

. Diagnostic and Statistical Manual of Mental disorders - DSM-5. 5th.ed. Washington: APA, 2013.

BENJAMIN, Harry. The Transsexual Phenomenon. New York: Julian Press, 1966.

BRASIL, Ministério da Saúde. Portaria no 1.707/GM, de 18 de agosto de 2008. Institui, no âmbito do SUS, o Processo Transexualizador, a ser implantado nas unidades federadas, respeitadas as competências das três esferas de gestão. Diário Oficial da União, Brasília, DF, 19 de agosto de 2008. Disponível em: <http://bvsms.saude.gov.br/bvs/saudelegis/gm/2008/prt1707_18_08_2008.html>.

Acesso em: 07 de ago. de 2018.

BUTLER, Judith. Corpos que Pesam: sobre os limites discursivos do sexo. In: LOURO, Guacira Lopes (Org.). O corpo Educado: Pedagogias da Sexualidade, pp. 110-125. Belo Horizonte: Autêntica, 2000.

. Lenguaje, Poder e Identidad. Madrid: Síntesis, 2009.

2017.

A vida psíquica do poder: teorias da sujeição. Belo Horizonte: Autêntica,

Problemas de gênero: feminismo e subversão de identidade. $8^{\mathrm{a}}$ ed. Tradução de Renato Aguiar. Rio de Janeiro: Civilização Brasileira, 2015.

Vol. 01, N. 04, Out. - Dez., 2018 - www.revistas.unilab.edu.br/index.php/rebeh 
CARVALHO, Renata. "Representatividade Trans Já - Diga Não ao Trans Fake". Agência Aids, 2018.2 Disponível em: <http://agenciaaids.com.br/artigo/representatividade-trans-ja-diga-nao-ao-trans-fake/>. Acesso em: 24 de jul. de 2018.

FOUCAULT, Michel. "Technologies of the self". In: Dits et écrits, pp. 783-813. Paris: Gallimard, Vol. IV, 1994.

A verdade e as formas jurídicas. Rio de Janeiro: Nau, 1999.

. O que é a crítica? Cadernos da F. F. C. Org. F. Biroli, M. C. Alvarez, UnespMarília-Publicações, v.9, n.1, p.169-89, 2000.

JESUS, Jaqueline. Homofobia: identificar e prevenir. 1 ed. Rio de Janeiro: Metanoia, 2015.

LIONÇO, Tatiana. Atenção integral à saúde e diversidade sexual no Processo Transexualizador do SUS: avanços, impasses, desafios. Physis, Rio de Janeiro, v. 19, n. 1, p. 43-63, 2009.

LEITE Jr, Jorge. Nossos corpos também mudam: a invenção das categorias "travesti" e "transexual" no discurso científico. São Paulo: Annablume, 2011.

MISKOLCI, Richard; PELUCIO, Larissa. Gênero, sexualidades e mídias contemporâneas: do pessoal ao político. Rev. Estud. Fem., Florianópolis, v. 25, n. 1, p. 263-268, Apr. 2017.

MONEY, John e TUCKER, Patricia. Os papéis sexuais. São Paulo, Brasiliense, 1981.

NUNES, Charô. "Blackface? Yes we can!". Blogueiras Negras, 2013. Disponível em: $<$ http://blogueirasnegras.org/2013/04/18/blackface-yes-we-can/>. Acesso em: 24 de jul. de 2018.

Organização Mundial da Saúde. Manual de classificação internacional de doenças, lesões e causas de óbitos - CID 09, 1975. São Paulo: Centro da OMS, 1978.

Classificação dos transtornos mentais e de comportamento - CID 10. Porto Alegre, RS: Artes Médicas, 1993.

PRECIADO, Paul. Manifesto contrassexual. São Paulo: n-1 edições, 2014.

Vol. 01, N. 04, Out. - Dez., 2018 - www.revistas.unilab.edu.br/index.php/rebeh 
RIBEIRO, Djamila. "Mulher negra não é fantasia de carnaval". Carta Capital, 2015. Disponível em: <https://www.cartacapital.com.br/blogs/escritorio-feminista/mulhernegra-nao-e-fantasia-de-carnaval-5190.html>. Acesso em: 24 de jul. de 2018.

RUBIN, Gayle. O tráfico de mulheres: notas sobre uma economia política do sexo. Recife, SOS, 1993.

STOLLER, Robert. A experiência transexual. Rio de Janeiro: Imago, 1982.

TRANSFAKE AND THE SEARCH FOR TRUTH IN “TRAVESTIS” AND TRANS PEOPLE REPRESENTATION

\begin{abstract}
This article discusses the way in which trans activism has criticized the interpretation of cis actors and actresses who play roles about transsexuality in scenic productions. These performances are called "transfake", in an attempt to rewrite the effects of "blackface" on trans population. Therefore, it was sought to question in what way the word "fake" would be, in opposition, maintaining a truth regime regarding gender, a common practice in psychiatric nosology history, but that can be found in certain current activists conducts. In this sense, disputes over representation have appeared as a way to prevent the relativization of transsexuality, because, although they aim to promote trans people political recognition, they also presume a certain correspondence between what one is and what one does. It is considered, therefore, that there are risks involved in defending identity stability, through censorship and prohibitive techniques, as well as the risks of fight against the possibilities of representing life.
\end{abstract}

Keywords: Trans activism; Transfake; Representation; Truth.

Recebido em: 03/09/2018

Aprovado em: 18/11/2018

Vol. 01, N. 04, Out. - Dez., 2018 -www.revistas.unilab.edu.br/index.php/rebeh 